$1-1-2011$

\title{
Variationist Approaches: External Factors Conditioning Variation in Spanish Phonology
}

Antonio Medina-Rivera

Cleveland State University, a.medinarivera@csuohio.edu

Follow this and additional works at: https://engagedscholarship.csuohio.edu/clmlang_facpub

Part of the Latin American Literature Commons, Spanish Linguistics Commons, and the Spanish Literature Commons

How does access to this work benefit you? Let us know!

Publisher's Statement

(c) 2011 Blackwell Publishing Ltd.

\section{Recommended Citation}

Medina-Rivera, Antonio. "Variationist Approaches: External Factors Conditioning Variation in Spanish Phonology." The Handbook of Hispanic Sociolinguistics. Ed. Manual Díaz-Campos. Malden, MA: WileyBlackwell, 2011. 36-53.

This Contribution to Books is brought to you for free and open access by the Department of World Languages, Literatures, and Cultures at EngagedScholarship@CSU. It has been accepted for inclusion in World Languages, Literatures, and Cultures Faculty Publications by an authorized administrator of EngagedScholarship@CSU. For more information, please contact library.es@csuohio.edu. 


\section{Variationist Approaches: External Factors Conditioning Variation in Spanish Phonology}

\section{ANTONIO MEDINA-RIVERA}

\section{Introduction}

During many years, studies in language variation had a special focus on phonological variation. In many ways the idea and concept of a linguistic variable, with two or more variants showing the same linguistic meaning but different social or stylistic values, adjusted perfectly to phonological studies. William Labov (1972) popularized a model on language variation to examine not only the importance of linguistic factors in showing language differentiation, but the incorporation of social and stylistic factors. This model examines interesting patterns of social stratification, and introduced the idea of careful vs. casual speech. In general, studies in Spanish linguistic variation follow the Labovian model as a way to explain differences in language use. Through the years, Labov's model of language variation has incorporated a strong statistical component, which originally started with basic percentages and has developed into more complex variable rule analyses to describe patterns of variation between alternative forms in language use (e.g. Varbrul, SPSS). ${ }^{1}$ In addition to variation studies, there is a long tradition of dialectological studies that has contributed immensely to the development of Spanish sociolinguistics. Many dialectological studies such as the pioneer research of Navarro Tomás, Zamora Vicente, Malmberg, and Lope Blanch have served as a starting point for many studies examining variation throughout the years.

This chapter will focus on the external factors conditioning phonological variation. I will introduce the traditional factors to analyze social variation (e.g. sex, age, social class) and stylistic variation (careful vs. casual speech), as well as other 
possible factors not fully explored in Spanish. These other factors are mostly inspired by Allan Bell's model of language style as audience design (1984), and Rickford and McNair-Knox's incorporation of addressee and topic of conversation as two important factors to analyze variation (1994).

\section{Social factors}

The incorporation of social variables in linguistic studies and the examination of levels of stratification might be considered the backbone of studies on language variation. Traditionally, the social factors included and analyzed are sex/gender, social class, and age. Labovian studies generally show a correlation between these social factors and the use or production of specific phonological variants. Among the generalizations established by many sociolinguists are:

- Women are more inclined to use more prestigious linguistic forms, whether those forms are standard or innovative.

- Men are more inclined to use more non-standard forms as well as variants with less prestige.

- Upper-middle class speakers tend to use more prestigious or standard forms, while lower-class people favor non-standard forms. The linguistic behavior of the middle class is rather more complicated, frequently making an effort to imitate speakers with higher socioeconomic status, but frequently resulting in ultracorrection and showing some levels of linguistic insecurity.

- Although most linguistic changes come from below (initiated within lower socioeconomic status speakers), there is evidence of some changes coming from above through education and media.

- Younger speakers have the tendency to be more innovative and are more likely to use non-standard forms, while the older generation seems to be more conservative. The middle-age group has a tendency to use more prestigious or standard forms depending on the marketplace. ${ }^{2}$

Besides the traditional social factors, other sociolinguists have incorporated additional social factors such as domains, level of education, marketplace, social networks, and relationships between speaker and interviewer. Social variables generate several complications for sociolinguists since some of them seem to be subjective, different from one culture to another, and difficult to control from a sociological and statistical perspective.

\subsection{The traditional social factors}

2.1.1 Sex/gender Differences in language use between men and women are fundamental to understand and examine language change. Dorothy Rissel (1989: 269) indicates that "Some early works focusing on Spanish asserted that the speech of women was more conservative than that of men." Taking into consideration 
data from different linguistic communities, William Labov (1990) established two basic principles for analyzing language differences between men and women: Labov's principles, which indicate that women tend to favor the use of more prestige forms, do not apply to all cultures.

Principle 1: For stable sociolinguistic variables, men use a higher frequency of nonstandard forms than women. In comparision with above, women favor the incoming prestige form more than men.

Principle 2: Comparing with below, women are most often the innovators. In fact, Janet Holmes (2001: 212) observes that: the generalization about women leading change towards the standard dialect applies only where women play some role in public social life. In Iran and India, for instance, it has been found that Muslim women's speech does not follow the Western pattern. In these places the status of women is relatively fixed and there is no motivation for them to lead linguistic change. It will not lead them anywhere socially. In these societies, women do not lead linguistic innovation in any direction.

In this chapter I will focus mainly on the research conducted by Spanish sociolinguists. For example, Gladys Cepeda (1990: 234) in her study of variable (s) in syllable final position with speakers from Valdivia, Chile shows minimal differences between middle-class men and women with frequencies of deletion of $16.0 \%$ and $15.9 \%$, respectively. Medina-Rivera (1997) in his study of velarization of $/ r /$ in syllable final position shows a similar pattern among middle-class speakers in Caguas, Puerto Rico with frequencies of non-standard velar variant for males and females of $8.4 \%$ and $10.4 \%$, respectively. Dorta (1989) in her study of liquids /r/ and $/ 1 /$ in La Perdoma, Tenerife shows no significant differences between men and women in the production of standard forms and weakened forms. Dorothy Rissel (1989: 276), on the contrary, in her study about assibilation of $/ r /$ among young people in San Luis Potosí, Mexico found that "young women assibilated more frequently than young men." In a similar case, Clara Wolf and Elena Jiménez (1979: 120-121), in their study about devoicing in Argentina's "yeísmo," show that women devoice with a frequency of $46 \%$ whereas men devoice with a frequency of $16 \%$.

The contradictions presented by the four studies mentioned above might be related to the social value of the change in each community; in other words, whether or not the innovative form carries prestige or stigma within the community. Cepeda, Medina-Rivera, and Dorta present phonological phenomena that are stigmatized, while Rissel and Wolf and Jiménez present variants that are gaining prestige among women of those communities.

Although linguistic behavior seems to be different for speakers with lower socioeconomic status, it is evident that among the middle class those differences seem to be minimal among Spanish speakers if the form in use has no prestige. Cepeda and Medina-Rivera presented minimal differences within the speakers they selected (all of them from the middle class). On the contrary, Rissel and Wolf and Jiménez focused on differences among speakers from different socioeconomic statuses. In her study, Dorta did not examine the correlation between sex and social class.

In Chapter 11 of this book, gender and variation is discussed in more detail. The exploration of linguistic differences among men and women in Spanish needs to be explained beyond the phonological boundaries. The Labovian principles for the 
study of language and sex were introduced at the beginning of this section. However, additional research is needed to confirm or contradict those principles in studies of the Spanish language. In fact, Labov (1990: 212) concludes, after analyzing cases from different languages, "Not all sociolinguistic variables show a sex effect."

21.2 Social class In some societies, defining social class seems to be uniform, with a clear hierarchical organization of the speech community; at least that seems to be the case for linguistic studies conducted in the United States or the United Kingdom. López-Morales (1979) and Dorta (1989) establish clear social differentiation for their studies in San Juan and Tenerife, respectively. Indicators such as education, occupation, or income (or a combination of all three), or other more subjective measures are useful to establish the socioeconomic status of an individual. Paola Bentivoglio and Mercedes Sedano (1993: 8) include in their studies a method to calculate a socioeconomic index, which includes: occupation of the speaker, occupation of the father, occupation of the mother, highest level of education acquired by the speaker, characteristics of the house where the speaker lives, total income of the family, and average income of the family. Sometimes people have the perception of belonging to one class or socioeconomic status, but by using sociological indicators they can be placed lower or higher on the scale. In addition, some societies have more social mobility than others, while other societies are more static and hierarchical. These are some of the difficulties when dealing with social class or socioeconomic status in linguistic studies. There are also complications in defining social class within rural communities when compared to urban communities, as presented by Marlene Broce and Rena Torres Cacoullos (2002).

In terms of language use in correlation with social class, Labov (1990: 220) concludes that "For a prestige marker, the higher a speaker's socioeconomic status, the higher the frequency of use. For a stigmatized variant, the reverse is true." Joan Bybee (2002: 283) suggests that "a number of researchers have challenged this position," and that "it is likely that gradual lexical diffusion occurs even in changes that turn out to be regular." Bybee also indicates (307) that "The strong directionality of such changes indicates that they are not the result of random variation, but that they stem from reduction processes resulting from repetition and the normal automation of motor activity." Matthew Alba (2006: 274) mentions that "a number of studies have shown that phonetic changes such as reduction and deletion often progress faster in higher-frequency items than in lower-frequency ones." These contradictions show that not all changes in language are equal, not all lexical tokens are equal, and that it is always necessary to examine additional factors besides social class and gender (such as frequency of use of a word) in order to explain a specific language change and/or to clarify those kinds of contradictions.

Dorta (1989: 88) in her study conducted in Tenerife indicates that middle-class and upper-middle class speakers favor the use of standard forms of $/ \mathrm{r} /$ more than speakers from the lower socioeconomic status: $52.8 \%$ of vibrant variants and $36.4 \%$ of weakened variants for the lower socioeconomic group vs. $59.7 \%$ of vibrant variants and $30.8 \%$ of weakened variants for the middle and upper-middle class group. Medina-Rivera (1997) uses level of education as the only indicator for his 
study in Caguas, Puerto Rico comparing language differentiation for speakers with a bachelor's degree or less and speakers with an education higher than a bachelor's degree. For the examination of variable $(r)$ in syllable final position, speakers with a bachelor's degree or less favored the non-standard variants with a frequency of $25.9 \%$ vs. $24.0 \%$ for speakers with an education higher than a bachelor's degree. In this case the results were not found significant by Varbrul or SPSS.

Gregory Guy (1988) examines four central problems related to language and class:

- the definition of class

- the description of language use

- the explanation of language change

- the construction of linguistic theory.

The examination of these four problems helps us to understand the motivation of language change for many societies, but at the same time leads us to reflect on how social class can also be related to race, ethnicity, and sex (Guy 1988: 48). For each society, each of these correlations is not necessarily the same. Social class is taken sometimes as a homogeneous concept, but the dynamics of many families can help us to understand how diverse and heterogeneous one family can be in terms of social class, wealth, level of education, and access to power.

Social class will not be examined in detail in this book. In fact, many Spanish sociolinguists seem to be discouraged by the problem of defining social class and incorporating it for their studies. It is clear, however, that people in power define and establish the prestigious forms in language. The role of education and media is fundamental in preserving certain standard or non-standard uses in language. Educators and news broadcasters make an effort to maintain a standard language that seems to be favorable to the highly educated people of one society. On the other hand, some talk shows and comedies popularize and glamorize the use of non-standard forms. These observations are fundamental when examining the different possibilities and sources for language change.

2.1.3 Age It is obvious that not all age groups speak the same or manipulate language in the same way. Age group analysis in sociolinguistic studies is fundamental if we are interested in showing or predicting language change. Although historical linguistics examines how language changes throughout the years, sociolinguistics is also interested in describing the process of change in apparent time. By examining differences in language use by three different generations (teenagers, adults, seniors) in present time, sociolinguists can predict possible changes within a community. Although it is not very common, some researchers have gone back to examine the language of speakers they had interviewed five or 10 years ago, and have obtained new data for their analysis (see Wolf and Jiménez 1979, and Wolf 1984 for a good example of language change through the years with the same speakers). Rickford and McNair-Knox's study (1994) is one of the few cases in English, and in Spanish one can mention the studies of Cedergren (1987) 
and Díaz-Campos (2003). Díaz-Campos does not necessarily include the same speakers from a previous study by Bentivoglio and Sedano (1989); however, his study incorporates speakers with the same demographic characteristics.

Carmen Silva-Corvalán (2001: 102) indicates that "el grupo que más propende a diferenciarse lingüísticamente es el de los adolescentes, quienes se identifican con su grupo esencialmente por medio del uso del vocabulario y expresiones propias de ellos y de su tiempo" (the group that is most likely to distinguish itself linguistically is adolescents, who identify themselves with their group by means of use of vocabulary and in-group expressions of their generation). Moreover, she suggests that many times, age interacts with many other related factors that need to be correlated in order to explain linguistic differentiation.

In his analysis of syllable final / $/$, López-Morales (1983), shows that older generations are more likely to produce the lateral variant /1/ than the younger generation, with a probability of occurrence of .46 for the younger group, and probabilities of .52 and .51 for the two other groups. López-Morales predicts a slight reduction of lateralization in the future of Puerto Rican Spanish. On the contrary, Medina-Rivera (1997) shows higher frequencies of lateralization for the younger generation than for the older generation, $33.4 \%$ and $23.1 \%$, respectively; discarding López-Morales's prediction. Although López-Morales's data was collected in San Juan and Medina-Rivera in Caguas, it is important to mention that both cities are within 15-20 minutes of each other, both studies included speakers from urban areas, and the two cities have experienced similar patterns of immigration during the last 40 years. This kind of result brings into evidence the difficulty of predicting language change. However, these results should not discourage sociolinguists. There is a need to develop new research and sociolinguistic projects in which age is the central element of analysis. Chapter 10 will take an in depth look at the complications of aging and variation.

2.1.4 Other social factors In addition to the traditional social constructs such as sex, socioeconomic status, and age, different scholars have experimented with other social factors to explain language behavior within a community or an individual. Domains and marketplace, social networks, and relationship between speaker and addressee are some of these other social factors that can help sociolinguists in examining language differences. Sex, socioeconomic status, and age seem to be more appropriate to explain linguistic shift within a community, whereas domain, social networks, and relationship with addressee seem to be more useful to explain differences between one individual and another.

As mentioned in the previous sections, sex, socioeconomic, and age can be useful to establish the patterns and directions of language change in a linguistic community. On the other hand, individual-based factors are highly useful to explain and understand linguistic differences within an individual or sub-group in a community.

The concept of domain was introduced by Fishman (1972) to explain the way in which speakers use language in different settings such as the ones provided by family, work, church, friends, and so on. This concept is helpful in showing how 


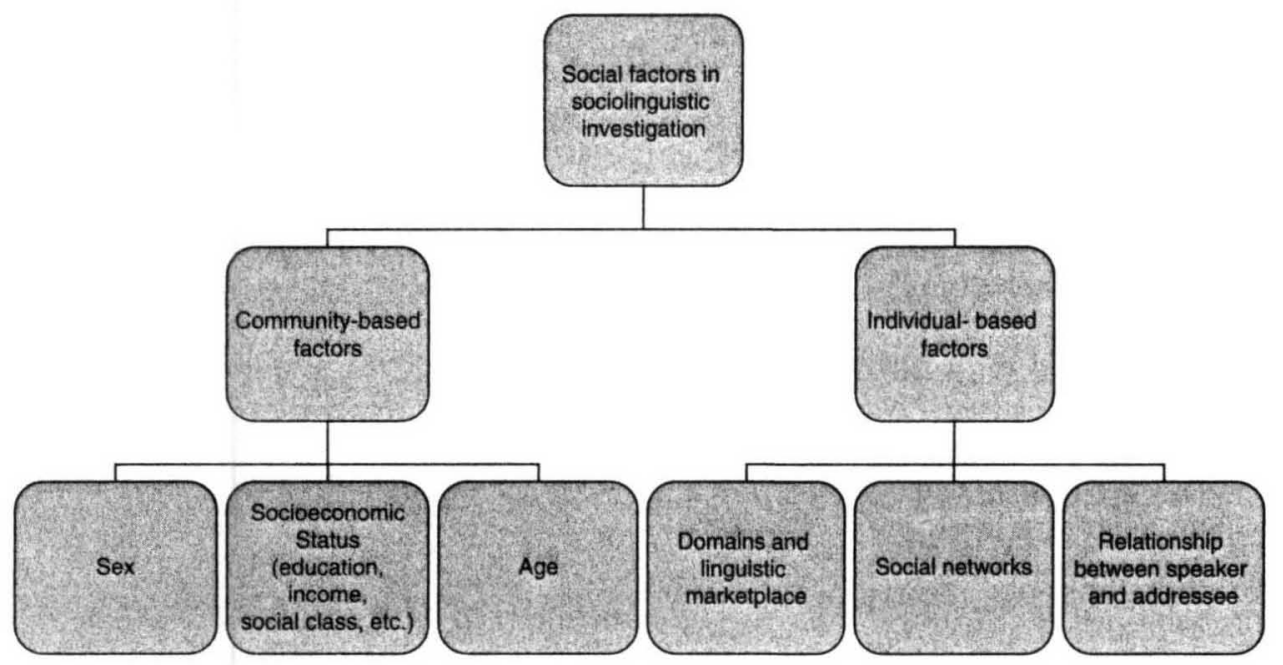

Figure 2.1 Diagram showing social factors. Source: Author.

speakers within the same community or within the same family may differ in their language use depending on the different domains in which they regularly socialize. Linguistic marketplace (Sankoff and Laberge 1978) refers to social interactions, and it is related to the social aspirations of each speaker and the behavior of speakers within a profession or social group. According to this concept, people have access to different linguistic forms depending on the environment surrounding them, the linguistic forms appropriate for a specific job, and what is valued in some specific interactions among individuals. Since domain and marketplace refer to social interactions they appeared as one category in Figure 2.1.

The concept of social networks was introduced by Milroy (1980) to describe how one individual relates to other people in a community or society. The strength of different social networks within an individual is going to have an impact on the language behavior of that specific individual. Social networks provide the individual with a speech repertoire that can go from the use of different varieties of the same language to the use of more than one language. The model of social networks implies following or examining one speaker's language through their different networks. Domain, marketplace, and social networks are very similar in nature; however, the concept of social networks seems to be more specific and broader than the other two.

The idea of considering the relationship between speaker and addressee is originally based on Bell's model of language as audience design (1984), which explains that a speaker accommodates to the audience or addressee. Rickford and McNairKnox (1994) examine the speẹch of Foxy, an African-American girl with two different interviewers (one is African-American, the other is White). The results of the study show that the race and familiarity of the addressee have an important effect on language production. Medina-Rivera (1997) divides the speakers of his study in 
Table 2.1 Production of non-standard variants according to the speaker's relationship to the interviewer (percentages and Varbrul probabilities).

\begin{tabular}{lccrr}
\hline & \multicolumn{2}{c}{ Variable $(r / l)$} & \multicolumn{2}{c}{ Variable $(r r)$} \\
\hline Known & $44.4 \%$ & .58 & $10.7 \%$ & .51 \\
Not Known & $24.4 \%$ & .39 & $7.8 \%$ & .49 \\
\hline
\end{tabular}

two groups: known by the interviewer, not known by the interviewer. The speakers, all of them from Caguas, Puerto Rico responded differently according to the relationship with the interviewer as shown in Table 2.1.

The results shown in lable 2.1 were not selected as significant by Varbrul; however, the differences between the speakers for the study of variable $(\mathrm{r} / \mathrm{l})$ are worth mentioning. Known speakers are more likely to produce non-standard variants than unknown speakers. Since all the speakers were from the same city, differences in race, age, and socioeconomic status between the interviewer and the speakers were not important.

Rickford and McNair-Knox's and Medina-Rivera's studies present two challenges to sociolinguistic studies: Does the race/age/social status/relationship of the interviewer have an important effect on the language production of the speakers? If this is true, then the ways of collecting data for sociolinguistic investigation can be challenged. It is also difficult to be precise in both studies about what has a major effect, the age, the race of the interviewer, and the addressee or the relationship between speaker and interviewer. Originally, Rickford and McNair-Knox and Medina-Rivera include relationship between speaker and interviewer as a stylistic factor; nevertheless this kind of relationship is more social in nature. The way one person relates to another, and the way both speakers accommodate their speech in order to interact, is related to all the other social factors mentioned before: age, socioeconomic status, and sex.

\section{Stylistic factors}

\subsection{The traditional stylistic factors}

Labov (1972: 79) introduced the concepts of careful vs. casual speech as parameters to study stylistic variation. He uses the formal interview as an example of careful speech "in which only one speaking style normally occurs." On the other hand, casual speech refers to instances in which the speaker is "paying much less attention to his own speech, and employs a more relaxed style." Labov adds other styles such as reading a paragraph or reading a list of words to establish the following continuum that goes from less to more attention paid to speech.

In Spanish, the incorporation of stylistic factors has not been very common. Barbara Lafford (1982) shows considerable differences between the frequencies for (s)-deletion in two distinctive styles: 


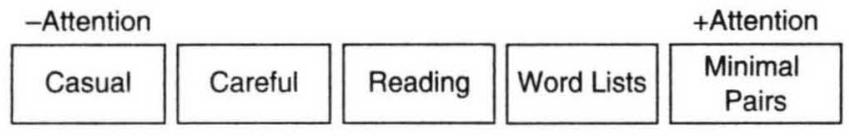

Figure 2.2 Diagram showing attention paid to speech. Source: Author.

Table 2.2 (s)-deletion in Cartagena.

\begin{tabular}{lcc}
\hline & \multicolumn{2}{c}{ Style } \\
\cline { 2 - 3 } Socioeconomic status & Informal & Reading a list of words \\
\hline Upper & $37 \%$ & $7 \%$ \\
Upper middle & $43 \%$ & $3 \%$ \\
Middle & $44 \%$ & $3 \%$ \\
Lower middle & $51 \%$ & $14 \%$ \\
Lower & $48 \%$ & $18 \%$ \\
\hline
\end{tabular}

Reading a list of words shows lower frequencies of (s)-deletion for speakers in all socioeconomic groups. Differences between the two styles are obvious, and the results are not surprising considering the attention speakers paid to speech when reading a list of words in comparison to an informal conversation.

Franceso D'Introno and J.M. Sosa (1986: 144) in their study of deletion of /d/ (in all phonological contexts) in Caracas Spanish also incorporate the traditional stylistic factors: a) spontaneous conversation, b) directed interview, and c) questionnaire to conclude that:

Que al pasar del estilo (a) al estilo (c) hay en cada nivel un incremento en el uso de la dental y consecuentemente un decrecimiento en el uso de las otras variantes. Por otro lado, el gráfico demuestra que las diferencias respectivas entre los tres niveles en el uso de la dental y la elisión quedan relativamente constantes en los dos estilos (a) y (c). (Upon moving from style (a) to style (c), there is incremental use of the dental variant and consequently, a decrease in the use of the other variants. On the other hand, the respective differences between the three levels of the use of the dental and elided variants remain relatively constant in styles (a) and (c).

D'Introno and Sosa's observations are also identical to those presented by Labov and Lafford, highly predictable and correlated with socioeconomic status as well.

\subsection{Other style-related factors}

Bell's model of language as audience design (1984) assumes that speakers mainly respond according to people around them, and in this sense, it is an accommodation model of convergence. Besides audience design, Bell mentions the possibility of non-audience design parameters such as setting and topic for analyzing 


\section{- Written Registers}

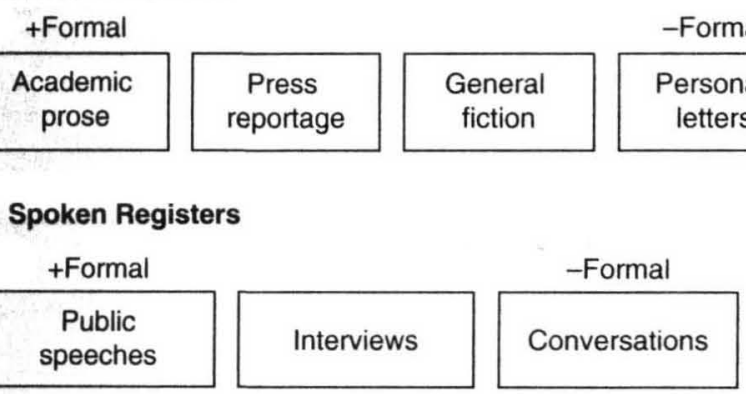

Figure 2.3 Diagram showing the register continuum. Source: Author.

language variation. As mentioned before, Rickford and McNair-Knox (1994), inspired in Bell's model, examine differences in language variation taking into consideration the race and relationship of speaker and interviewer, topic of conversation and setting. They conclude that the speakers accommodate to the speech of the interviewer, and use standard or non-standard forms depending on the topic of conversation and the addressee.

Finegan and Biber (1994) prefer the term register variation; however, I am not going to establish differences between stylistic and register variation in this chapter. They use the parameters of opportunity for careful speech, purpose, and degree of shared context to explain the linguistic differences of situational variation. Finegan and Biber examined phonological, grammatical, discourse, and lexical elements to establish those differences. Taking into consideration these three parameters, they create a continuum that goes from more to less formal, and that includes both written and spoken registers:

Type of situation, topic of conversation, and type of discourse are analyzed in the following sections as parameters for stylistic variation. The first one is an audience design parameter, while the last two are non-audience design.

3.2.1 Type of situation Bell (1984: 179) indicates that "the effect of setting is not readily available, probably because systematic changes in setting are (a) harder to organize than for topic, and (b) likely to co-occur with other changes." In fact, very few studies follow the same speaker in different speech environments or settings. It requires additional time from both the investigator and the speaker. Finegan and Biber (1994) include differences between interview and public speech, although they do not suggest examining the same speaker performing in both registers. Labov et al. (1968) introduced the group situation in a study about African-American vernacular in Harlem. The study concluded that adolescents are more likely to produce more vernacular forms when interacting with each other in a group situation.

Medina-Rivera $(1997,1999)$ included three types of situations in his study with young adults in Caguas, Puerto Rico: group situation, interview, and oral presentation (in order of formalitv). The interview is the regular guided conversation used by most 
Table 2.3 Probability of production of non-standard variants for two phonological variables: type of situation.

\begin{tabular}{lcc}
\hline & $\begin{array}{c}\text { Variable }(r / l) \\
\text { lateralization }\end{array}$ & $\begin{array}{c}\text { Variable }(\mathrm{rr}) \\
\text { velarization }\end{array}$ \\
\hline Group & .66 & .85 \\
Interview & .54 & .41 \\
Oral presentation & .16 & .40 \\
\hline
\end{tabular}

sociolinguists, and the group situation is similar to Labov's (a group of peers during a meal or any other informal gathering). The oral presentation is equivalent to the public speech, using speakers who perform this kind of activity as part of their regular work practices: for example a dental hygienist who educates a group of patients before undertaking a treatment, a church or community leader meeting with people for an educational presentation, and so on. A basic requirement for an oral presentation in this study was that it should not be read (of course notes were acceptable) to keep all three situations as oral registers or styles.

Table 2.3 shows the production of non-standard variants for two different phonological variables according to the type of situation.

The results for both variables are statistically significant and show the impact of the type of situation on speech selection. The probabilities also support the ability speakers have to accommodate to a different audience. Group situations, which in the case of this study were more spontaneous and not guided, show the highest probabilities of production of non-standard variants.

Four out of 20 young adult speakers in the study had the opportunity to participate in all three situations. All four speakers were among the participants "known" by the interviewer. As mentioned by Bell it is not easy to obtain data for this kind of parameter; however, for this study it was fundamental to show the patterns of language variation among a population of young adult speakers with a mid- to high level of education. The group situation and the oral presentation are similar in terms of having a larger audience than the one-on-one interview; nevertheless, the purpose is differentiated (taking into consideration Finegan and Biber's parameters). The purpose of the group situation is to share in a friendly environment, whereas the oral presentation is to educate a group of people on a specific topic. In the group situation "the speaker" is actively interacting with others, while in the oral presentation most of the speech is performed by "the speaker" and the audience is limited to some comments or questions.

3.2.2 Topic of conversation Bell (1984) and Rickford and McNair-Knox (1994) examine the importance of the topic in language variation. The speaker shows important differences in language selection according to the topic of conversation. Each topic is different in nature and brings about different connections, experiences, and settings. Speakers are also more passionate about some topics than others. Table 2.4 shows some of these differences in topic shifting: 
Table 2.4 Frequency of non-standard variants for two phonological variables: topic of conversation.

\begin{tabular}{lcrr}
\hline & $\begin{array}{c}\text { Variable }(r / l) \\
\text { lateralization }^{3}\end{array}$ & \multicolumn{2}{c}{$\begin{array}{c}\text { Variable }(r r) \\
\text { velarization }\end{array}$} \\
\hline Childhood & $44.9 \%$ & $25.5 \%$ & .73 \\
Friends & $52.0 \%$ & $10.3 \%$ & .50 \\
Moment of Embarrassment & $55.9 \%$ & $23.0 \%$ & .74 \\
Sad Moment & $56.1 \%$ & $9.6 \%$ & .54 \\
Hobbies & $57.9 \%$ & $13.6 \%$ & .64 \\
Moment of Danger & $59.8 \%$ & $6.2 \%$ & .35 \\
Family & $60.8 \%$ & $14.3 \%$ & .57 \\
Work & $65.6 \%$ & $6.0 \%$ & .44 \\
School & $66.0 \%$ & $7.7 \%$ & .47 \\
Abortion & $72.3 \%$ & $16.1 \%$ & .79 \\
Capital Punishment & $74.3 \%$ & $11.1 \%$ & .69 \\
Politics & $77.5 \%$ & $4.0 \%$ & .33 \\
Happy Moment & $81.0 \%$ & $9.4 \%$ & .60 \\
\hline
\end{tabular}

Although this factor was accepted as significant by SPSS $(\mathrm{p}<.05)$, there are not consistent patterns for both variables, even though lateralization and velarization carry a stigma among the population. Varbrul only found significant topic of conversation for the running of the step up and down of variable (rr) (see probabilities of occurrence in the right side of the table). Topics on "abortion" and "capital punishment" show high frequencies or probabilities for both variables. Both topics give us the idea of being elements for a more complex discourse; however, people were very passionate when talking about these controversial topics. In other words, not only the topic might be important to show language variation, but also the attitude or reaction the speaker might have on that specific topic. That reaction might vary from speaker to speaker within the same speech community, so the results might not be very consistent. Rickford and McNair-Knox (1994) concluded that the speaker they examined in the study used more vernacular forms when speaking about familiar topics ("wives and slamming partners" vs. "school and career"), but at the same time it seems that the familiarity of the speaker with the interviewer had a major impact in language shifting.

Topic of conversation is a very interesting parameter to analyze; it is also rather easy to control in a sociolinguistic interview. However, this parameter can easily interact with other factors such as emotions, relationship with the addressee, knowledge about that topic, and so on.

3.2.3 Type of discourse The last stylistic parameter in this section is language variation according to the type of discourse used by the speaker. Bell's study (1984: 178) includes topic of conversation and setting as non-audience design parameters, 
Table 2.5 Probabilities of non-standard variants for two phonological variables: type of discourse.

\begin{tabular}{lcc}
\hline & $\begin{array}{c}\text { Variable }(r / l) \\
\text { lateralization }\end{array}$ & $\begin{array}{c}\text { Variable }(r r) \\
\text { velarization }\end{array}$ \\
\hline Dialogue & .59 & .72 \\
Narrative & .58 & .56 \\
Other discourse genres & .48 & .47 \\
\hline
\end{tabular}

or non-personal factors derived from audience design. In addition to those two, Ialso included type of discourse, since one cannot imply that speech is homogeneous across the board in terms of language use and variation. In general, one can distinguish among five types of discourse: dialogue, description, exposition, narrative, and argumentation. Booth and Gregory (1987: 54-55) use the following example to describe each type of discourse genre:

If we have to give a speech to convince the editorial board to elect our friend as editor for the coming year, we might use some description (of the newspaper's situation at the present time), some narration (a story about how our friend behaved in a crisis last spring), some exposition (of the standards that any editor ought to meet), and some argumentation (about how the precise qualities of our friend meet the standards and the situation as we laid them out).

This example provides a clear distinction for four of the discourse genres. "Dialogue" is not mentioned in the example but it can be used for those other instances in the conversation in which both the speaker and the addressee make short one-to-one comments or produce sequences of short questions and answers (De Oliveira e Silva and Tavares de Macedo 1992: 237). Medina-Rivera (1997) includes this parameter in his study of lateralization of syllable final $/ \mathrm{r} /$ and velarization of trill / $\mathrm{rr} /$ as shown in Table 2.5.

Argumentation, description, and exposition form the group "other discourse" in this study, and they were grouped for statistical purpose (a common practice when running Varbrul, especially, as was the case for this study, if the values/frequencies between two or more variants are very similar). The results are statistically significant and show the importance of considering differences in type of discourse for analyzing variation. Consistently, dialogue and narrative favored non-standard variants more than the other discourse genres. It is necessary to examine the structure and dynamics of each discourse genre in order to understand the differences more clearly. Intuitively, one can suggest that narrative is more dynamic since it involves events and action, and also that argumentation/exposition is slower in tempo because it involves opinions and values. On the other hand, one can say that some people are very passionate when defending an opinion. Does attention paid to speech have a role in language usage for each one of the discourse genres? More studies are necessary in order to have a more complete scenario of this fascinating stylistic parameter. 


\section{Social and stylistic factors vs. linguistics factors}

What is more important in a sociolinguistic investigation: the internal factors or the external factors conditioning variation? According to Bell (1984) the social dimension is more important and relevant than the stylistic dimension, and according to Preston (1991) the linguistic dimension is more important and relevant than the social one. These ideas are summarized in Bell's Style Axiom and Preston's Status Axiom:

(1) Style Axiom: Variation on the style dimension within the speech of single speaker derives from and echoes the variation which exists between speakers on the social dimension. (Bell 1984: 151)

(2) Status Axiom: Variation on the status dimension derives from and echoes the variation which exists within the linguistic dimension. (Preston 1991: 36)

The way to justıty these two proposals is by showing a larger range of variability along the dimensions associated by the linguistic, the social, or the stylistic factors. Preston compares these ranges of variability by looking at the probabilities of occurrence shown in different studies that incorporate Varbrul for the statistical analysis. Medina-Rivera (1997) challenges both axioms as one can observe in Table 2.6.

Table 2.6 shows that the greater variation of space occurs for stylistic factors, specifically for type of situation: a range from .16 to .66 with a difference of .50 in one study, and a range from .40 to .85 with a difference of . 45 in the other. Topic of conversation has a space of .46, with a range from .33 to .79 . The studies that Preston examines do not include type of situation, topic of conversation, or type of discourse, but are limited to the traditional parameters of casual vs. careful speech, formal vs. infor$\mathrm{mal}$, and superior vs. inferior. There is no need to reestablish the axiom to indicate hierarchy in variation. Every study is different: hence, it is fundamental to always take into consideration the influence of internal and external factors in sociolinguistic research.

\section{Summary and conclusion}

External factors conditioning linguistic variation are essential for sociolinguistic investigation. No study can be limited to only examine internal or linguistic factors, since external factors can provide additional and important information to understand language shifting within a community and within a person. The number of articles focused on social and stylistic factors is somehow limited, and/ or are submitted to the traditional Labovian parameters.

There are several complications when dealing with social and stylistic variables in sociolinguistic investigations that deserve further investigation such as:

Social and stylistic factors interact with each other, making it difficult to determine which of the external factors is the basic or fundamental one to explain language shifting or variation. 
Table 2.6 Varbrul probabilities of non-standard variants for two studies on phonological variation.

\begin{tabular}{|c|c|c|c|}
\hline \multicolumn{2}{|l|}{ Variable $(r /)$} & \multicolumn{2}{|l|}{ Variable $(r r)$} \\
\hline \multicolumn{2}{|l|}{ Linguistic dimension } & \multicolumn{2}{|l|}{ Linguistic dimension } \\
\hline \multicolumn{2}{|l|}{1 Morphematic value } & \multicolumn{2}{|l|}{1 Word class } \\
\hline Morphematic & .46 & Proper nouns & .33 \\
\hline Non-morphematic & .52 & Other words & .52 \\
\hline Porque & .57 & & \\
\hline \multicolumn{4}{|l|}{2 Stress } \\
\hline Stressed syllable & .57 & & \\
\hline Unstressed syllable & .38 & & \\
\hline \multicolumn{2}{|l|}{ Social dimension } & \multirow{3}{*}{\multicolumn{2}{|c|}{$\begin{array}{l}\text { Social dimension } \\
1 \text { Relationship of speaker } \\
\text { and interviewer }\end{array}$}} \\
\hline \multirow{4}{*}{$\begin{array}{l}1 \text { Parents' education } \\
\text { High school or less } \\
\text { College education }\end{array}$} & & & \\
\hline & \multirow{3}{*}{$\begin{array}{l}48 \\
57\end{array}$} & & \\
\hline & & Known & .51 \\
\hline & & Not known & .49 \\
\hline \multicolumn{4}{|c|}{$\begin{array}{l}2 \text { Relationship of } \\
\text { speaker and interviewer }\end{array}$} \\
\hline Known & .58 & & \\
\hline Not known & 39 & & \\
\hline \multicolumn{2}{|l|}{ Stylistic dimension } & \multicolumn{2}{|l|}{ Stylistic dimension } \\
\hline \multicolumn{2}{|l|}{1 Type of discourse } & \multicolumn{2}{|l|}{1 Type of discourse } \\
\hline Dialogue & .59 & Dialogue & .72 \\
\hline Narrative & .58 & Narrative & .56 \\
\hline Other discourses & .48 & Other discourses & .47 \\
\hline \multicolumn{2}{|l|}{2 Type of situation } & \multicolumn{2}{|l|}{2 Type of situation } \\
\hline Group & .66 & Group & .85 \\
\hline Interview & .54 & Interview & .41 \\
\hline \multirow{7}{*}{ Oral presentation } & .16 & Oral presentation & .40 \\
\hline & & \multicolumn{2}{|c|}{3 Topic of conversation } \\
\hline & & Politics & .33 \\
\hline & & Moment of danger & .35 \\
\hline & & Childhood & .73 \\
\hline & & $\begin{array}{l}\text { Moment of } \\
\text { embarrassment }\end{array}$ & .74 \\
\hline & & Abortion & .79 \\
\hline
\end{tabular}

- Some factors (e.g. type of situation) require additional effort or field work for the investigator; however, the incorporation of such factors provides a more complete scenario on language variation and change.

- If one wants to focus on one specific external factor, how do we control many other external factors that can be affecting variation for that specific linguistic 
variable? These kinds of issues are of special interest for other social scientists as well, and as sociolinguists, we need to think from an interdisciplinary perspective in order to deal with these kinds of complications.

- If the dialect of the interviewer and the speaker is different, how do we compensate for that important difference?

- The correlation between language and media can also be of great use to understand and examine stylistic differences, although it might be controversial due to the fact that it is a factor difficult to measure and to control.

* There are many new sources available for sociolinguists such as YouTube, Windows Messenger, and Skype, that can create interest in a new generation of language specialists, and that open new possibilities to analyze language variation.

- Following the same speakers through the years as done by Wolf and Jiménez and Rickford and McNair-Knox seems to be an interesting challenge to analyze variation in real time.

There is no doubt that we can add more complications and areas of further research to this list. However, it is necessary to expand the horizons of research in phonological variation and experiment with other non-traditional factors, and for Spanish sociolinguists to experiment with factors or issues that have been addressed for other languages, but not fully explored in Spanish.

\section{NOTES}

1. Varbrul is a set of statistical analysis methods commonly used in sociolinguistics and historical linguistics to describe patterns of variation between alternative forms in language use. SPSS is a computer program used for statistical analysis. In 2009 it was re-branded as PASW (Predictive Analytics SoftWare).

2 The term marketplace introduced by David Sankoff and Suzanne Laberge is used to explain the extent to which a profession/job or activity is associated with use of more standard language.

3 I am only including the weights for the analysis of variable (rr), since this factor was not selected as significant by Varbrul for variable ( $r / 1)$.

\section{REFERENCES}

Alba, Matthew. 2006. Accounting for variability in the production of Spanish vowel sequences. In Nuria Sagarra and A.J. Toribio (eds) Selected Proceedings of the Ninth Hispanic Linguistics Symposium, 273-285. Somerville, MA: Cascadilla Proceedings Project.
Bell, Allan. 1984. Language style as audience design. Lang. Soc. 13. 145-204.

Bentivoglio, Paola and M. Sedano. 1993. Investigación sociolingüística: sus métodos aplicados a una experiencia venezolana. Boletin de Linguística 8. 3-36. 
Booth, Wayne C. and M. W. Gregory. 1987. Writing as thinking: thinking as writing. New York: Harper and Row.

Broce, Marlene and Rena Torres Cacoullos. 2002. "Dialectología urbana" rural: la estratificación social de (r) y (l). Hispania 85.2. 342-353.

Bybee, Joan. 2002. Word frequency and context use in the lexical difusión of phonetically conditioned sound change. Language Variation and Change 14. 261-290.

Cedergren, Henrietta J. 1987. The spread of language change: verifying inferences of linguistic diffusion. Georgetown University Round Table on Languages and Linguistics, 45-60.

Cepeda, Gladys. 1990. La variación de /s / en Valdivia: sexo y edad. Hispania 73 (1). 232-237.

De Oliveira e Silva, Giselle M. and Alzira Tavares de Macedo. 1992. Discourse markers in the spoken Portuguese of Rio de Janeiro. Language Variation and Change 4. 235-249.

Díaz-Campos, Manuel. 2003. The pluralization of haber in Venezuelan Spanish: a sociolinguistic change in real time. IU Working Papers in Linguistics 3. 6.

D'Introno, Francesco and J.M. Sosa. 1986. Elisión de la /d/ en el español de Caracas: aspectos sociolingüísticos e implicaciones teóricas. In H.J. Cedergren et al. (eds), Estudios sobre la fonología del español del Caribe, 135-163. Caracas: La Casa Bello.

Dorta Josefa. 1989. Las líquidas /r/ y /1/ en La Perdoma. In Josefa Dorta and Juana Herrera (eds), Tres estudios de fonética, 72-129. Spain: Secretariado de Publicaciones.

Finegan, Edward and Douglas Biber. 1994. Register and social dialect variation: an integrated approach. In Douglas Biber and Edward Finegan (eds), Sociolinguistic perspectives on register, 315-347. New York: Oxford University Press.

Fishman, Joshua. 1972. The sociology of language: an interdisciplinary social science approach to language in society. Rowley, MA: Newbury House.

Guy, Gregory. 1988. Language and social class. In Frederick J. Newmeyer (ed.), Language: the socio-cultural context, 37-63. New York: Cambridge University Press. Holmes, Janet. 2001 (1992). An introduction to sociolinguistics, second edition. Harlow, UK: Longman.

Labov, William. 1972. Sociolinguistic patterns. Philadelphia: University of Pennsylvania Press.

Labov, William. 1990. The intersection of sex and social class in the course of linguistic change. Language Variation and Change 2. 205-254.

Labov, William, P. Cohen, C. Robins and J. Lewis. 1968. A study of the nonstandard English of Negro and Puerto Rican speakers in New York City. Final report, Cooperative Research Project 3288. 2 vols. Philadelphia: U.S. Regional Survey.

Lafford, Barbara A. 1982. Dynamic synchrony in the Spanish of Cartagena, Colombia. Cornell University dissertation.

López-Morales, Humberto. 1979. Dialectología y sociolingüística: temas puertorriqueños. Madrid: Hispanova.

López-Morales, Humberto. 1983. Estratificación social del español de San Juan de Puerto Rico. México: Universidad Nacional Autónoma de México.

Medina-Rivera, Antonio. 1997. Phonological and stylistic variables in Puerto Rican Spanish, University of Southern California dissertation.

Medina-Rivera, Antonio. 1999. Variación fonológica y estilística en el español de Puerto Rico. Hispania 82. 529-541.

Milroy, Lesley. 1980. Language and social networks. Oxford: Blackwell.

Preston, Dennis. 1991. Sorting out the variables in sociolinguistic theory. American Speech 66. 33-56.

Rickford, John R. and Faye McNair-Knox. 1994. Addressee and topic-influenced style shift: a quantitative sociolinguistic study. In Douglas Biber and Edward Finegan (eds), Sociolinguistic perspectives 
on register, 235-276. New York: Oxford University Press.

Rissel, Dorothy A. 1989. Sex, attitudes, and the assibiliation of $/ \mathrm{r} /$ among young people in San Luis Potosí, Mexico. Language Variation and Change 1. 269-283.

Sankoff, David and Suzanne Laberge. 1978. The linguistic market and the statistical explanation of variability. In David Sankoff (ed.), Linguistic variation: models and methods, 239-250. New York: Academic.

Silva-Corvalán, Carmen. 2001. Sociolinguística y pragmática del español. Washington, DC: Georgetown University Press.

Wolf, Clara. 1984. Tiempo real y tiempo aparente en el studio de una variación lingüística: ensordecimiento y sonorización del yeísmo porteño. In L. Schwarz and I. Lerner (eds), Homenaje a Ana María Barrenechea, 175-196. Madrid: Castalia.

Wolf, Clara and E. Jiménez. 1979. El ensordecimiento del yeísmo porteño. In Ana María Barrenechea (ed.), Estudios lingüísticos y dialectológicos: temas hispánicos, 115-145. Buenos Aires: Hachette. 